Table 1. Weibull regression model for first remission, adjusted by gender and disease duration

\begin{tabular}{lcccc}
\hline Covariate & \multicolumn{2}{c}{ Multivariable full model } & Multivariable reduced model \\
\cline { 2 - 5 } HR 95\% Cl & $\mathrm{p}$-value & $\mathrm{HR} \mathrm{95 \%} \mathrm{Cl}$ & $\mathrm{p}$-value & \\
Age & $1.02(0.94,1,11)$ & 0.53 & & \\
Age at Diagnosis of PsA & $0.98(0.90,1.07$ & 0.7048 & & \\
BMI & $0.97(0.93,1.00)$ & 0.0824 & $0.96(0.92,0.99)$ & 0.02 \\
Axial & $0.85(0.85,1.99)$ & 0.2276 & & \\
NSAIDs & $0.71(0.46,1.10)$ & 0.1224 & & 0.009 \\
DMARDs & $1.14(0.74,1.75)$ & 0.5592 & & \\
Biologics & $1.69(1.11,2.57)$ & 0.0150 & $1.73(1.15,2.61)$ & \\
Diabetes & $0.57(0.24,1.34)$ & 0.1984 & & \\
Infection & $1.60(1.00,2.56)$ & 0.0518 & & \\
Depression/Anxiety & $0.60(0.31,1.16)$ & 0.1302 & & \\
Elevated ESR & $0.68(0.41,1.13)$ & 0.1400 & & \\
Gender (male vs female) & $1.10(0.72,1.68)$ & 0.6696 & $1.10(0.73,1.67)$ & 0.64 \\
Disease Duration & $0.95(0.87,1.04)$ & 0.2967 & $0.97(0.95,1.00)$ & 0.05 \\
\hline
\end{tabular}

$\mathrm{Cl}$ - confidence interval; BMI-Body Mass Index; NSAIDs- nonsteroidal anti-inflammatory drugs; DMARDs- disease modifying anti-rheumatic drugs; ESR- erythrocyte sedimentation rate

having remission (no actively inflamed joints for 12 months). However, we did not take into account the other domains of the disease.

Objectives: We aimed to test the concept of remission as the absence of disease manifestations in PsA, determine the frequency of remission in our PsA cohort, and identify predictors for remission.

Methods: PSA patients followed between 2000 and 2015 were included. Patients are assessed at 6- to 12-month intervals according to a standard protocol, which includes the information necessary for minimal disease activity (MDA) assessment. Remission was defined as a visit that patients had no tender or swollen joints, no inflammatory back pain, no tender entheseal sites, minimal skin involvement with $\mathrm{BSA}<1 \%$, patient pain on visual analog scale (VAS) score of $<15$, patient global disease activity VAS score of $<20$, Health Assessment Questionnaire (HAQ) score $<0.5$. We used imputation to determine remission status for each patient and did a sensitivity analysis including only visits with all information available. We fit a Weibull regression model with interval/right censored and left truncated data adjusted for sex and disease duration at baseline. Both multivariable full model and reduced model with Hazard Ratio (HR), 95\% confidence interval $(\mathrm{Cl})$ estimates, and p-value are provided in Table1.

Results: 985 patients $(57 \%$ males, mean age 47.4 yrs Table) were included. Using imputation 175 (18.2\%) patients had remission at least once and 107 (10.9\%) achieved sustained remission. In the sensitivity analysis, 109 (10.9\%) patients achieved remission at least once, and 48 $(4.9 \%)$ sustained remission for 2 consecutive visits. Using baseline variables with imputation, only BMI was significant and lowered the chance of remission. In the sensitivity analysis no baseline variables were significant. Using a model with time varying covariates higher BMI lowered the chance of remission, while use of biologics increases the chance of remission. Similar results were obtained with the sensitivity analysis. Only biologics predicted sustained remission.

Conclusion: We defined remission as a state of no clinical activity. Remission occurred in $18 \%$ of patients with PsA at least once and was sustained in 11\%. High BMI reduced and use of biologic agents increased the chance of sustained remission.

Disclosure of Interests: Samar Al Harbi: None declared, Ker-Ai Lee: None declared, Vinod Chandran: None declared, Richard Cook: None declared, Dafna D Gladman Grant/research support from: AbbVie, Amgen, Celgene, Lilly, Novartis, Pfizer, and UCB, Consultant for: AbbVie, Amgen, BMS, Celgene, Galapagos, Gilead, Janssen, Lilly, Novartis, Pfizer, and UCB

DOI: 10.1136/annrheumdis-2019-eular.7248

\section{SAT0361 CARDIOVASCULAR RISK FACTORS AND COMORBIDITIES IN PATIENTS WITH PSA, RA AND THE GENERAL POPULATION}

Anton Landgren ${ }^{1}$,Lennart T.H. Jacobsson ${ }^{1}$, Mats Dehlin ${ }^{1}$, Ulrika Bergsten ${ }^{2}$, Eva Klingberg ${ }^{1} .{ }^{1}$ Institute of Medicine, Dept of Rheumatology and Inflammation Research, Sahlgrenska Academy, Gothenburg, Sweden, Gothenburg, Sweden; ${ }^{2}$ Research and Development Department at Region Halland, Halmstad, Sweden, Halmstad, Sweden

Background: Patients with psoriatic arthritis ( $\mathrm{Ps} A$ ) have previously been reported to have increased cardiovascular morbidity and mortality compared to psoriasis, rheumatoid arthritis (RA) and the general population
(GP). Obesity has been linked to an increased risk of developing PsA and to be higher in patients with PsA compared to those with psoriasis, RA and GP. Furthermore, obese patients with PsA are more likely to have high disease activity and a reduced response to treatment. Few studies have reported on life style data in combination with traditional cardiovascular risk factors in patients with PsA compared to GP and RA in the same setting

Objectives: We aimed to assess cardiovascular risk factors in patients with PsA compared to age- and sex matched RA and GP subjects.

Methods: We performed a cross-sectional study in the Western Sweden Health Care Region (WSHCR). All Individuals who were $>18$ and had at least one ICD-10 diagnosis for PSA (ICD-10 codes M073) or RA (ICD 10 codes M059 and M060), at a visit at any of three rheumatology clinics in the WSHCR during a two-year period (Jan 2015 through Feb 2017) were identified. From these we randomly selected PsA patients $(n=1200)$ and RA patients $(n=1246)$, with equal sex distribution and they were sent a postal questionnaire. Data for non-responders were limited to age and sex.

The questionnaire included questions on demographics, comorbidities, smoking, alcohol consumption, physical activity, medications and disease specific entities. The National public health survey from 2015, "Health on equal terms", which was sent to randomly selected citizens in Sweden aged 16-84, was used as a sex- and aged matched reference population with five controls matched per RA and PsA case. Obesity was defined according to $\mathrm{WHO}$ standards as $\mathrm{BMI} \geq 30$. Daily smoking, alcohol consumption ( $\geq 5$ standard drinks of alcohol per week) and physical activity ( $\geq 3$ hours per week) were also analyzed.

Results: Response rates were $n=687$ (57.3\%) for PsA and $n=742$ $(59.6 \%)$ for RA. After age- and sex matching there were 432 individuals with PsA, 431 with RA and 4314 matched subjects from the general population left for analyses. Mean age was 61.1 (SD 12.0) years and $42 \%$ males in all three groups. Patients with PsA were more frequently obese, compared to both GP $(p<0.001)$ and RA $(p=0.012)$. Smoking was more prevalent in RA and PSA than in GP. In addition, hypertension was more common in PsA compared to RA $(p=0.044)$ and GP $(p<0.001)$ Diabetes was also more prevalent in PsA than in GP $(p=0.007)$, as was hyperlipidemia $(p=0.039)$. Patients with PsA drank more often $\geq 5$ standard drinks of alcohol per week than patients with RA did $(p=0.046)$. Conclusion: In PsA, obesity and comorbidities related to CVD were increased above what was seen for both RA compared to the GP. This highlights the need to address these partly modifiable factors in particular for patients with PsA

Disclosure of Interests: Anton Landgren: None declared, Lennart T.H. Jacobsson Consultant for: LJ has received lecture and consulting fees from Pfizer, Abbvie, Novartis, Eli-Lily and Janssen, Mats Dehlin: None declared, Ulrika Bergsten: None declared, Eva Klingberg Grant/research support from: Unrestricted grant from Roche, Consultant for: Novartis, Speakers bureau: Speakers fee from Lilly

DOI: 10.1136/annrheumdis-2019-eular.4662

Table 1. characteristics of PsA, RA and GP subjects

\begin{tabular}{|c|c|c|c|c|c|c|}
\hline & $\begin{array}{l}\text { PsA, } \\
n=432\end{array}$ & $\begin{array}{c}\mathrm{RA}, \\
\mathrm{n}=431\end{array}$ & $\begin{array}{c}\text { GP, } \\
n=4314\end{array}$ & $\begin{array}{l}\text { p-value } \\
\text { (PsA vs } \\
\text { RA) }\end{array}$ & $\begin{array}{l}\text { p-value } \\
\text { (RA vs } \\
\text { GP) }\end{array}$ & $\begin{array}{l}\text { p-value } \\
\text { (PsA vs } \\
\text { GP) }\end{array}$ \\
\hline BMI, mean (std) & $\begin{array}{l}27.4 \\
(4.8)\end{array}$ & $\begin{array}{l}26.3 \\
(4.6)\end{array}$ & $\begin{array}{l}26.4 \\
(4.3)\end{array}$ & 0.001 & 0.705 & $<0.001$ \\
\hline $\mathrm{BMI} \geq 30, \mathrm{n}(\%)$ & $\begin{array}{c}98 \\
(22.7)\end{array}$ & $\begin{array}{c}69 \\
(16.0)\end{array}$ & $\begin{array}{c}739 \\
(17.1)\end{array}$ & 0.012 & 0.555 & $<0.001$ \\
\hline Daily smoker, n(\%) & $37(8.6)$ & $\begin{array}{c}55 \\
(12.8)\end{array}$ & $\mathrm{N} / \mathrm{A}$ & 0.046 & $\mathrm{~N} / \mathrm{A}$ & $\mathrm{N} / \mathrm{A}$ \\
\hline $\begin{array}{l}\geq 5 \text { standard drinks of alcohol } \\
\text { per week, } n(\%)\end{array}$ & $\begin{array}{c}92 \\
(21.3)\end{array}$ & $\begin{array}{c}69 \\
(16.0)\end{array}$ & $\mathrm{N} / \mathrm{A}$ & 0.046 & $\mathrm{~N} / \mathrm{A}$ & $\mathrm{N} / \mathrm{A}$ \\
\hline $\begin{array}{l}\text { Physical activity } \geq 3 \text { hours } \\
\text { per week, } n(\%)\end{array}$ & $\begin{array}{c}224 \\
(51.9)\end{array}$ & $\begin{array}{c}205 \\
(47.6)\end{array}$ & $\begin{array}{l}2354 \\
(54.6)\end{array}$ & 0.208 & 0.005 & 0.289 \\
\hline Diabetes, $\mathrm{n}(\%)$ & $\begin{array}{c}52 \\
(12.0)\end{array}$ & $42(9.7)$ & $356(8.3)$ & 0.167 & 0.301 & 0.007 \\
\hline Myocardial infarction, n(\%) & $28(6.5)$ & $25(5.8)$ & $\mathrm{N} / \mathrm{A}$ & 0.501 & $\mathrm{~N} / \mathrm{A}$ & $\mathrm{N} / \mathrm{A}$ \\
\hline Stroke, $\mathrm{n}(\%)$ & $16(3.7)$ & $15(3.5)$ & $\mathrm{N} / \mathrm{A}$ & 0.675 & $\mathrm{~N} / \mathrm{A}$ & $\mathrm{N} / \mathrm{A}$ \\
\hline Gout, n(\%) & $25(5.8)$ & $19(4.4)$ & $\mathrm{N} / \mathrm{A}$ & 0.199 & $\mathrm{~N} / \mathrm{A}$ & $\mathrm{N} / \mathrm{A}$ \\
\hline Kidney disease, n(\%) & $9(2.1)$ & $11(2.6)$ & $\mathrm{N} / \mathrm{A}$ & 0.814 & $\mathrm{~N} / \mathrm{A}$ & $\mathrm{N} / \mathrm{A}$ \\
\hline Hypertension, n(\%) & $\begin{array}{c}195 \\
(45.1)\end{array}$ & $\begin{array}{c}170 \\
(39.4)\end{array}$ & $\begin{array}{l}1350 \\
(31.3)\end{array}$ & 0.044 & $<0.001$ & $<0.001$ \\
\hline Hyperlipidemia, n(\%) & $\begin{array}{c}94 \\
(21.8)\end{array}$ & $\begin{array}{c}70 \\
(16.2)\end{array}$ & $\mathrm{N} / \mathrm{A}$ & 0.039 & $\mathrm{~N} / \mathrm{A}$ & $\mathrm{N} / \mathrm{A}$ \\
\hline
\end{tabular}

